\title{
Erratum to: Forskolin Induces Hyperphosphorylation of Tau Accompanied by Cell Cycle Reactivation in Primary Hippocampal Neurons
}

\author{
Hai-Hong Wang ${ }^{1} \cdot \operatorname{Yan} \mathrm{Li}^{1} \cdot$ Ang $\mathrm{Li}^{1} \cdot$ Fang Yan $^{1} \cdot$ Zhen-Lin $\mathrm{Li}^{1} \cdot$ Zhong-Ying Liu ${ }^{1}$. \\ Lei Zhang ${ }^{1}$ - Jian Zhang ${ }^{2}$ - Wei-Ren Dong ${ }^{1}$ - Lin Zhang ${ }^{1}$
}

Published online: 7 February 2017

(C) Springer Science+Business Media New York 2017

Erratum to: Mol Neurobiol

DOI 10.1007/s12035-016-0348-7

The original version of this article unfortunately contained an error on Panel A of Figure 7. The last two immunoblots are incorrect.

The authors hereby publish the corrected Figure 7 as presented below.

The online version of the original article can be found at http://dx.doi. org/10.1007/s12035-016-0348-7

Wei-Ren Dong

wrdong@163.com

$\triangle$ Lin Zhang

zlilyzh@126.com

1 Department of Histology and Embryology, School of Basic Medical Sciences, Southern Medical University, Guangzhou 510515, China

2 Department of Oncology, Zhujiang Hospital of Southern Medical University, Guangzhou 510280, China 
A

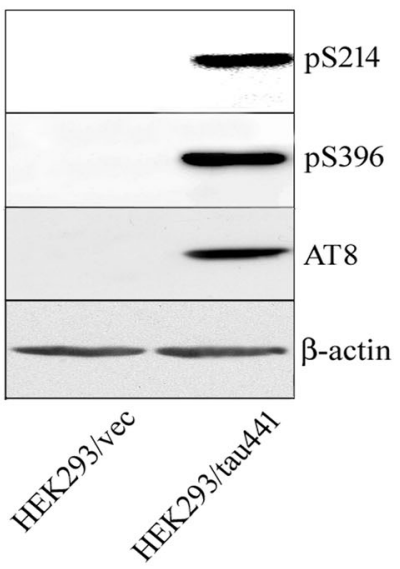

B

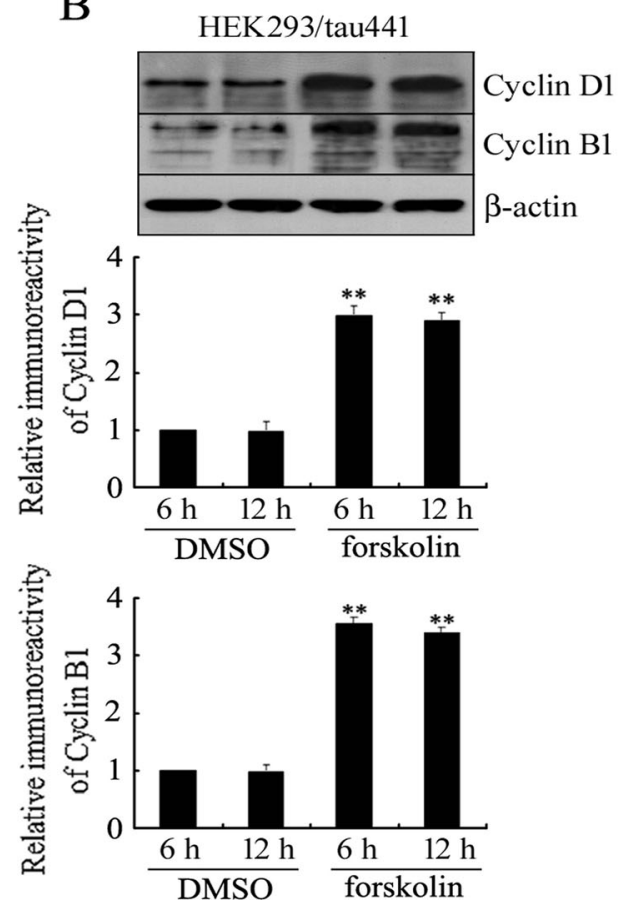

C
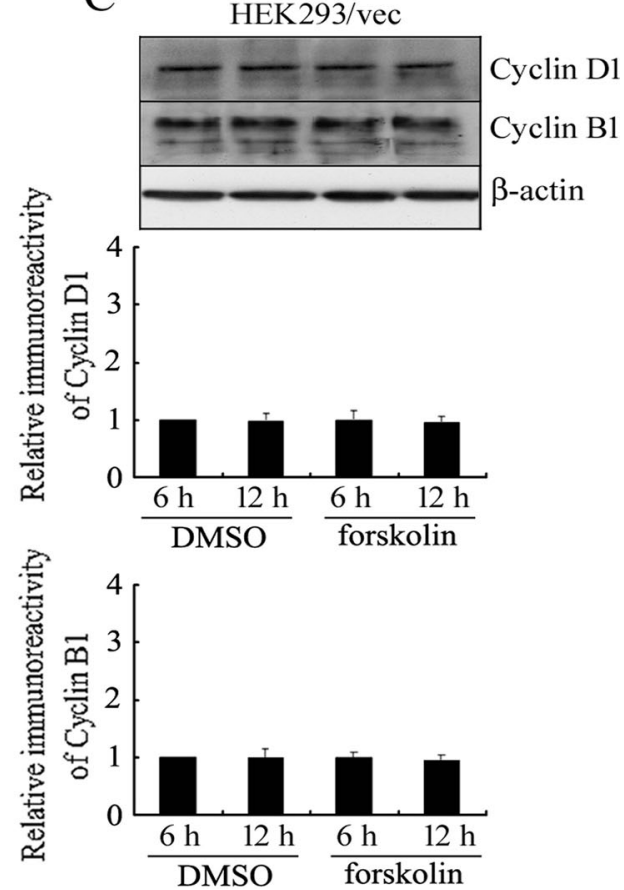